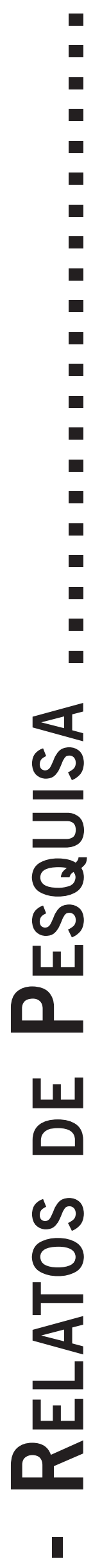




\title{
O CLUBE DO LIVRO IDENTIDADE: UMA ANÁLISE FENOMENOLÓGICA E GESTÁLTICA
}

\author{
The Identity Book Club: a phenomenological and gestaltical analysis \\ El Club del Libro Identidad: un análisis fenomenológico y gestáltico
}

Diego Paulino Galhardo

Ondina Pena Pereira

\begin{abstract}
Resumo: A leitura é uma forma de nos achegarmos a nós próprios para possibilitar o surgimento daquilo que se oculta de nós mesmos, do outro que nos habita, isso porque, com a leitura, apreendemos o texto, discurso ou livro, de uma forma muito particular, conforme nossa subjetividade, e deixamos de ser "leitores" para nos tornar novos "autores" do que foi lido. Um importante fenômeno nesse processo diz respeito à desleitura, que pode ser considerada um ato em que o sujeito leitor se apropria do que está lendo, tornando sua a obra em questão - a obra com que está entrando em contato - dando-lhe continuidade, retificando trechos, ratificando experiências similares e etc., dando-lhe, assim, um significado todo pessoal. Pensando nessa forma de ler, subjetiva, pessoal e vivencial, isto é, para além de uma forma intelectualizada e objetivada, este artigo trata-se de analisar, em termos fenomenológicos e gestálticos, as reuniões do Clube do Livro Identidade, o qual é um clube de leitura de estudantes do IFB que se reuniram mensalmente para discussão de obras literárias.
\end{abstract}

Palavras-chave: Desleitura; Gestalt-terapia; Fenomenologia; Grupo terapêutico.

\begin{abstract}
The reading is a way for us to draw close to ourselves in order to make it possible for the emergence of what is hidden from ourselves, of the other that we dwell, this is because, by the reading, we have learned from the text, speech or book, in a very particular way, as our subjectivity, and we are no longer "readers" to make us new "authors" of what was read. An important phenomenon in this case concerns about the misreading, which can be considered as an act in which the subject player appropriates of which is reading, making his the book in question, giving it continuity, grinding passages, ratifying similar experiences and etc., giving it a very personal meaning. Thinking on this way of reading, subjective, personal, and experiential, which is, in addition to a form intellectualized and targeted, this article intends examining, in a phenomenological and gestaltical terms, the meetings of the Identity Book Club, which is a IFB students club of reading who met monthly for discussion of literary works.

Keywords: Misreading; Gestalty-therapy; Phenomenology; Therapeutic group.
\end{abstract}

Resumen: La lectura es un medio de nos acercar a nosotros mismos con el fin de hacer posible el surgimiento de lo que se oculta de nosotros, de los otros que nos habita, esto porque, por medio de la lectura, aprendemos el texto o libro, de una forma muy particular, conforme nuestra subjetividad, dejando de ser "lectores" para nos tornar nuevos "autores" de la obra lida. Un importante fenómeno en ese proceso es la deslectura, que puede ser considerada un ato en el que el sujeto lector se apropria de lo que está leyendo, tomándolo para si la obra en cuestión - la obra con que se está entrando en contacto - dandole continuidad, corrigiendo extractos, ratificando experiencias similares y etc., dandole, así, un significado todo personal. Pensando en esa forma de leer, subjetiva, personal y vivencial, quiero decir, además de una forma intelectualizada y objetivada, este artículo se trata de analisar, en termos fenomenológicos y gestálticos, los encuentros del Club del Libro Identidad, que es un club de lectura de los estudiantes de IFB que se encontraron una vez por mês para la discusión de obras literarias.

Palabras-clave: Deslectura; Gestalt-terapia; Fenomenología; Grupos terapéuticos.

\section{Introdução}

A leitura é uma forma de nos achegarmos a nós próprios para possibilitar o surgimento daquilo que se oculta de nós mesmos, do outro que nos habita (Freire, 2000), isso porque, com a leitura, apreendemos o texto, discurso ou livro, de uma forma muito particular, conforme nossa subjetividade, e deixamos de ser "leitores" para nos tornar, pelo menos, "coautores" do que foi lido.

Por meio da leitura, podemos ter ganhos primários, tais como uma melhora na capacidade de nos expressar, verbal e literariamente, da nossa capacidade cognitiva / intelectual e maior chance de nos apropriarmos e de nos adaptarmos ao mundo contemporâneo, atribuindo-lhe significados (Paixão, 2002; Torre, 2012).

Temos exemplos de alguns benefícios, através de experimentos grupais, que a prática da leitura pode trazer a seus participantes.

Paixão (2002), por meio de uma análise fenomenológica, dissertou sobre as mudanças que a aquisição da leitura permite à pessoa, no que se refere à posição que esta ocupa em relação às outras pessoas do seu meio social. Ela averiguou, ao analisar o comportamento em sala de aula de crianças em torno de 07 e 10 anos de idade, que 
"adquirir, pois, a habilidade de leitura, capacita o sujeito a ampliar seus horizontes tanto em termos de participação cultural, como em termos de pensamento e atribuição de significados a sua existência e a existência dos outros" (p. 34).

Torre (2012), em tese de doutorado, encontrou ganhos que dizem respeito à habilidade de leitura e escrita de estudantes do Ensino Fundamental e Médio de Portugal (os quais estavam abaixo da média europeia) por meio de participação em clubes virtuais de leitura (CVL), tendo verificado, assim, o "incremento da motivação, das capacidades sociais e comunicativas e da compreensão (...) reflexão sobre o modo como vêem o mundo, designadamente os valores, as tradições e as culturas" (p. 65).

No entanto, nosso foco aqui é o de um experimento grupal no qual se coloca em observação os aspectos subjetivos do leitor em relação com uma obra literária, considerando o ato de ler não somente como ato cognitivo, mas também como ato psicológico.

A ideia de que tal interação entre um sujeito leitor e uma obra literária seja possível nos vem a partir da concepção de desleitura, que pode ser considerada como o ato em que o sujeito leitor se apropria do que está lendo, tornando sua a obra em questão - a obra com que está entrando em contato - dando-lhe continuidade, retificando trechos, ratificando experiências similares e etc. dando-lhe, assim, um significado todo pessoal (Bloom, 1991; Proust, 1991).

A desleitura se refere a esse movimento de interpretação ou falsificação que o escritor/leitor faz de seu predecessor, uma vez que "a leitura, como o título indica, é um ato tardio e inteiramente impossível que, quando forte, trata-se sempre de uma desleitura" (Bloom, 2003, p. 23) em complemento com a ideia de que "se conhecemos um texto o que conhecemos é a interpretação que fazemos dele” (p. 83).

Nesta pesquisa, tomamos o fenômeno da desleitura não como algo exclusivo de poetas e demais escritores, mas sim como algo possível e provável a qualquer sujeito leitor que se dispõe a entrar em contato com alguma obra literária, que se dirige a essa obra literária numa intencionalidade (sentido de intentio) própria da Fenomenologia

Para Bloom, "um leitor, quando entende um poema, está de fato entendendo a sua própria leitura deste poema” (1991, p. 117). No mesmo caminho, Proust afirma que "nossa sabedoria começa onde a do autor termina” (1991, p. 30). Já em Silva (2008, p. 14), uma experiência de leitura aproximada desse tipo seria um ato de colocar a memória do que é lido lado a lado com a memória do que é/foi vivido.

Levando em consideração a forte relação entre Psicologia e Literatura, Leite (2002) afirma que os leitores são pessoas diferentes, cada uma com sua personalidade e subjetividade. E por meio destas diferenças, resultam diferentes interpretações que uma obra literária pode fornecer. $\mathrm{O}$ ato de ler não engloba somente uma atitude, mas também envolve uma experiência e uma apropriação de determinado conteúdo por meio do pensamento, da atenção, da percepção, da memória, da imaginação e da inteligência. Por isso, o sujeito leitor, por meio das diferentes interpretações e leituras advindas de sua singularidade, também cria, elabora, imagina e realiza um pensamento produtivo e criador, semelhante ao sujeito escritor em seu processo de criação.

Nesse sentido, desde o princípio hermenêutico heideggeriano (Freire, 2000), pode-se afirmar mesmo que, para que haja uma real apropriação do texto pelo leitor, é necessária a constituição de um campo intersubjetivo, onde o sujeito leitor se torna sujeito autor. O que envolve, segundo Bloom "o ato de ser influenciado pelo poema e de influenciar qualquer outro leitor para quem seja comunicada sua leitura” (1991, p. 107).

O contato com a literatura (de um modo específico) e a arte (de um modo geral) permite esse crescimento pessoal, pois a arte não tem apenas uma função recreativa e estética, como também é um ótimo instrumento para que o sujeito que está em contato com ela inicie um processo de reconhecimento e autoconhecimento.

\section{Objetivos}

O objetivo geral deste relato de pesquisa é realizar uma análise de um experimento grupal (numa concepção de grupo gestáltica e rogeriana) a partir de um clube de leitura, o Clube do Livro "Identidade", oportunidade na qual reunimos um grupo de pessoas para discussão - desde seus aspectos subjetivos, tais como memórias, ideias, pensamentos, sentimentos e etc. - de obras literárias (romances, em sua totalidade) previamente lidas.

Na análise das sessões, usamos do arcabouço teórico da Fenomenologia (que será mais explicitada no próximo item) e da Gestalt-terapia.

A Gestalt-terapia vê o ser humano como um ser de relação (relação consigo mesmo, com o mundo e com os outros) e propicia um espaço que potencializa a criatividade da pessoa no enfrentamento das questões relevantes de sua atualidade existencial (Fonseca, 2005).

A partir da análise das sessões literárias, buscamos evidenciar o caráter promotor de saúde mental e de autoconhecimento que tal prática terapêutica e alternativa - para além da prática tradicional de consultório clínico e de atendimento individual - pode fornecer aos seus participantes.

\section{Metodologia}

Esta é uma pesquisa de base qualitativa, para cuja realização, utilizamos o método fenomenológico.

Prioriza, o método fenomenológico, a compreensão da experiência vivida através do resgate da essência de determinado fenômeno, essência essa que diz respeito a aspectos da referida experiência que são comuns a todos os participantes de um grupo de pesquisa (Moreira, 2002, 
p. 114). Dessa forma é que se orientou o método fenomenológico de pesquisa em sua construção. Em Holanda (2003), vemos que o objetivo da pesquisa fenomenológica é alcançar os significados atribuídos pelas pessoas em relação à situação pesquisada.

O método fenomenológico de investigação passa por três momentos básicos: a descrição fenomenológica, que expressa e retrata a experiência consciente do sujeito; a redução fenomenológica, que consiste na reflexão dos conteúdos descritos; e a interpretação fenomenológica, onde, através de uma relação dialógica entre pesquisador e pesquisado, ocorre a compreensão do acontecimento vivido por ambos (Martins, 1992).

Na descrição fenomenológica, na qual se busca explicitar a experiência consciente da pessoa, há esse movimento na tentativa de descrever a experiência vivida do sujeito, e não "explicar” ou justificar essa experiência, tal como no método positivista de pesquisa (Martins, 1992).

Pela redução fenomenológica, ou epoché - suspensão do juízo, não aceitando e nem refutando, não afirmando e nem negando (Abbagnano, 2007, p. 339) - tem-se o momento para a reflexão da vivência anteriormente descrita das pessoas participantes da pesquisa. Para Holanda (2003, p. 50), a redução fenomenológica contém dois momentos distintos e entrelaçados: o envolvimento existencial - o qual consiste na abertura à vivência que se está investigando, deixando fora de ação os conhecimentos adquiridos sobre ela, colocando entre parênteses todo o conhecimento que se tem a priori de tal fenômeno - e o distanciamento reflexivo, onde há a postura que adota o pesquisador, postura essa que possibilita a compreensão e a captação do sentido que subjaz à vivência à sua descrição.

Para a interpretação fenomenológica, Martins e Bicudo (1989) destacam a importância da elaboração das unidades de significados, as quais contêm o insight psicológico das reuniões da pesquisa e que são construídas em relação à perspectiva que o pesquisador tem em relação ao fenômeno, transformando a linguagem coloquial e de senso comum do sujeito de pesquisa em discurso psicológico inteligível conforme o referencial teórico usado pelo pesquisador.

Uma prática comum nas pesquisas de cunho fenomenológico e muita usada nesta pesquisa é a Versão de Sentido, a qual consiste em "uma fala expressiva da experiência imediata da pessoa, diante de um encontro recém-terminado. Quando registrado por escrito, é um texto breve, escrito livre e espontaneamente" (Amatuzzi, 1996, p. 11). Para Holanda (2003, p. 50) é "um 'relato livre e espontâneo' da experiência imediata do sujeito”.

\subsection{O Clube do Livro Identidade}

O Clube do Livro Identidade (que veio a se chamar assim por meio de deliberação coletiva) se caracteriza por ser um clube de leitura de 05 alunas do Instituto Federal de Brasília (IFB), local onde foram realizadas as reuniões, que aconteceram ao longo do primeiro semestre de 2015, registradas em áudio, no total de seis encontros, sendo três delas sessões propriamente ditas de discussão de romances, com aproximadamente 01 hora de duração cada uma, uma vez por mês, e as outras três para a formação do Clube e do fechamento da pesquisa (sessão de feedback e uma entrevista individual com cada participante).

As sessões literárias ocorreram através das obras Orgulho e preconceito (1813) de Jane Austen (1775-1817), O perfume (1985) de Patrick Süskind (1949-) e O grande Gatsby (1925) de F. Scott Fitzgerald (1896-1940).

A pesquisa como um todo se deu em seis momentos chaves, as fases A, B, C, D, E e F.

Na Fase A, tivemos o processo de formação pessoal através de participações em outros clubes de leitura, a fim de se ter uma maior experiência e ideias com vistas ao manejo e condução de um grupo com essas características.

Na Fase B, tivemos o contato com a instituição, estabelecimento da parceria institucional, negociação de certificado para os participantes e resolução de demais pendências burocráticas.

Na Fase C, tivemos o convite aos participantes para a composição do Clube do Livro Identidade, seja por encaminhamento dos alunos atendidos pela CDAE (Coordenação Geral de Assistência Estudantil e Inclusão Social) ou por inscrição aberta a todos que se interessarem, respeitando o limite de 15 vagas.

Na Fase D, tivemos a primeira reunião do Clube do Livro Identidade, com o estabelecimento do contrato psicológico, da assinatura do Termo de Consentimento Livre e Esclarecido, da explicação do que se espera dos participantes e do conceito de desleitura (a partir de alguns exemplos pessoais do próprio facilitador do grupo) que tentamos colocar em prática nas reuniões.

Na Fase E, tivemos as sessões propriamente ditas de discussão, onde se reuniram os alunos com o facilitador do grupo, oportunidade na qual, também, ao final de cada sessão, cada participante escreveu e entregou sua respectiva versão de sentido.

Na Fase F, tivemos o encerramento da pesquisa, com a sessão final de feedback, entrevista individual e investigação fenomenológica através das versões de sentido escritas e do retorno aos participantes, confirmando com eles nossas impressões a respeito de todo o processo.

Dentro dos limites deste artigo, importa-nos aqui detalhar a Fase F, isto é, a investigação fenomenológica.

\section{Resultados}

Realizamos a investigação fenomenológica a partir das unidades de significados coletadas durante a redução fenomenológica das sessões literárias, das versões de sentido, da sessão final de feedback da pesquisa e das entrevistas individuais, sendo essas duas últimas (sessão final e entrevistas individuais) o momento em que nos 
voltamos aos participantes da pesquisa com o que escrevemos sobre eles buscando sua convalidação para uma construção conjunta da análise.

As unidades de significados envolvem os pontos mais significativos, conforme a pesquisa, e que estão mais presentes de acordo com a fala dos participantes.

Não pretendemos afirmar que - apesar de coletadas durante as sessões literárias correspondentes a cada obra em questão - as unidades de significados aqui descritas apareçam com certa frequência em outras reuniões literárias com as mesmas obras em questão; ao contrário, essas unidades de significados foram coletadas conforme a singularidade de cada encontro, construído por meio da subjetividade (experiências pessoais) de cada participante no encontro, tornando cada reunião um evento único.

As unidades de significado que foram coletadas são: a normatização da sociedade; a awareness sensorial; e a autonomia pessoal. Devido a sua importância no processo, também destacamos um tópico para a versão de sentido.

\subsection{A normatização da sociedade}

Na sessão literária sobre Orgulho e preconceito, a unidade de significado (isto é, as partes mais chamativas conforme um prisma de investigação e que mais apareceram nos diferentes discursos) mais presente, experimentada e discutida pelos participantes foi a obrigação de uma mulher se casar para ter uma posição na sociedade. Se essa posição é alta ou baixa, depende do nível econômico e social de seu marido. Em suas versões de sentido, Fabiana (tendo em vista a orientação do Comitê de Ética de Pesquisa, todos os nomes aqui citados são fictícios) chegou a frisar como "as mulheres desde pequenas eram incentivadas a pensar no casamento (...) o quanto a mulher era pressionada a casar. Hoje acontece isso só que de uma maneira diferente" e Raquel a se incomodar com que "mesmo hoje em dia muitas mulheres acham que tudo que podem fazer da vida delas é casar e ter filhos".

No confronto de opiniões acerca do casamento que foram discutidas no grupo, consideramos um efeito positivo o fato de todos se manifestarem a partir de suas vivências ou das experiências de terceiros, encontrando abrigo ou sentimentos próximos compatíveis ao emitir suas ideias sobre o assunto.

As reflexões sobre a posição de submissão da mulher numa relação conjugal foi uma das primeiras demandas do feminismo branco ocidental, por exemplo.

Trazendo essa influência da sociedade sobre o indivíduo (no contexto da Inglaterra Rural retratada no livro) para uma época mais presente (década de 20 do século $\mathrm{XX)}$, percebemos que também essa temática apareceu na discussão de $O$ grande Gatsby, onde vemos o protagonista patrocinando festas e mais festas para convidados que mal conhecia, esbanjando o luxo da própria casa e dos carros, mostrando as caras roupas e pertences à amante $\mathrm{e}$ etc. numa tentativa de obter reconhecimento e prestígio aos olhos dos outros.

Ora, pensando nos termos do mundo contemporâneo, vemos como a sociedade normatiza muitos padrões de comportamento individual fazendo com que a pessoa aja não só da forma que não quer ou que não precisa, mas que também, muitas vezes, aja conforme uma disposição contrária ao seu potencial.

A Gestalt-terapia busca denunciar normatizações do comportamento, as quais, muitas vezes, pretendem perpetuar um sistema de domesticação das potencialidades humanas ou tentam manter um determinado status quo de dominação de uma classe sobre outra e assim, consequentemente, apontar os diversos "deverias" que a sociedade nos passa enquanto concidadãos (Perls, 1988, p. 131, grifo nosso):

A ideia da terapia Gestalt é transformar pessoas de papel em pessoas reais... E fazer o homem inteiro de nosso tempo vir à vida, e ensiná-lo a usar seu potencial inato... Todas estas ideias parecem muito pretensiosas, mas acredito que é possível que possamos fazer isto agora, que não temos que deitar no divã por anos, décadas e séculos sem mudanças essenciais... Nas décadas precedentes o homem da sociedade viveu para o que é certo, e fez seu trabalho sem se importar se realmente queria fazê-lo ou se era talhado para ele. Mas toda a sociedade estava regida e regularizada pelo "deveria" (shouldism).

Podemos refletir sobre tais interesses de terceiros, que não somente têm como procedência determinadas ideologias e filosofias de vida, mas que também abarcam campos de interesse econômico e político.

No campo econômico, é notória a evolução do capitalismo industrial para o capitalismo de consumo, o qual continuamente tenta nos passar a sensação de falta, que será satisfeita com a compra de produtos. Anderson (1999, p. 68) contextualiza o homem pós-moderno (contemporâneo) como um sujeito que vai da exaltação, da corrida às mercadorias, do eufórico entusiasmo do espectador ou consumidor para a depressão do vazio niilístico mais profundo do nosso ser.

Segundo Perls (1980, p. 30), estamos vivendo uma época de incongruência e incompatibilidade entre as necessidades do indivíduo e as necessidades da sociedade, não porque a natureza "errou" em relação às necessidades do indivíduo, mas porque a sociedade passou por um processo longe de seu funcionamento salutar, não permitindo que as necessidades da sociedade e as do indivíduo ajustem-se entre si.

Um interessante experimento a se realizar nessa temática seria pedir às participantes que dividissem uma folha de papel em quatro espaços e colocassem: no primeiro espaço, coisas que gostam de fazer e fazem; no segundo espaço, coisas que gostam de fazer e não fazem; no 
terceiro espaço, coisas que não gostam de fazer e fazem; e no quarto espaço, coisas que não gostam de fazer e não fazem. A discussão poderia se enriquecer com a exposição por parte de cada um, para o grupo, acerca de questões impostas pela sociedade e como lidam com essas questões encaixando-as com as próprias demandas internas; o que pode resultar numa intensa reflexão do papel que a sociedade (traduzidas em demandas externas, alheias ao nosso potencial) tem em nossa vida cotidiana.

\subsection{Awareness sensorial}

A awareness é a capacidade de aperceber-se do que se passa dentro e fora de si no momento presente, em nível corporal, mental e emocional (Perls et al, 1997). Também é conhecida como autoconsciência, tomada de consciência, conscientização, insight ou autodescoberta, e consiste em aprender a discernir o que nos faz sentir bem e o que nos faz sentir mal, a obter mais informação sobre nós mesmos (quem sou, como me machuco, o que quero, do que preciso), ou seja, a descobrir nosso processo interno sobre nós mesmos e para nós mesmos (Resnick, 1977).

A pessoa se "autoconscientiza" captando sensações e sentimentos que a acompanham e, assim, compreende o mundo, a si mesma e a sua experiência no mundo (Polster, 2001). Para Enright (1980, p. 342), envolve uma direcionalidade do eu em relação ao mundo, onde há um enfraquecimento momentâneo da barreira eu-mundo, numa percepção imediata da situação corrente.

Na sessão literária sobre O perfume, Fabiana nos trouxe a experiência de como resolveu prestar mais atenção em seu olfato em determinadas situações. Bárbara, na versão de sentido correspondente, destacou que “'Percepção’ é a minha palavra chave para o dia de hoje" e que se sente "mais cautelosa para absorver coisas que por algum motivo passariam sem a devida atenção”. Em Gestalt-terapia, há uma especial atenção à forma pela qual o sujeito usa de seus órgãos do sentido para possibilitar o seu contato com o ambiente.

Perls (1988) estabelece quatro formas pelas quais o sujeito bloqueia a conscientização de um saudável contato organismo-meio, a saber: a projeção; a introjeção; a retroflexão; e a dessensitivação. Interessa-nos aqui, conforme essa unidade de significado, a dessensitivação, a qual envolve um processo de embotamento sensorial da pessoa, que não "ouve" o que se passa ao seu redor, que não se "apercebe" de tal objeto na sala e etc. Uma das tarefas do terapeuta, neste caso, é trabalhar pela recuperação da sensibilidade da pessoa, ou seja, pelo desbloqueio de seus sentidos.

A Gestalt-terapia é uma prática que nos aperfeiçoa a aptidão de vivermos no presente (Resnick, 1977), devido à grande relevância que se dá ao aqui e agora da relação e da existência quando, por exemplo, num ambiente clínico, o consulente é orientado a suspender o raciocínio para intensificar a auto-observação e expressar o que se passa em seu campo atual de consciência (Naranjo, 1980, p. 78). Thera (1962/2005, p. 44) nos leva a refletir sobre o tempo infrutífero quando demasiadamente nos desligamos do aqui e agora:

How much energy has been wasted by useless thoughts of the past: by longing idly for bygone days, by repetition in word or thought, of all the banalities of the past! Of equal futility is much of the thought given to the future: vain hopes, fantastic plans and empty dreams, ungrounded fears and useless worries.

Quanta energia se desperdiçou em inúteis pensamentos do passado; suspirando ociosamente por dias idos, por fúteis arrependimentos e a repetição insensata e tagarela, em palavras e pensamentos, de todas as banalidades do passado! De igual futilidade é muito do pensamento dado ao futuro: esperanças vãs, planos fantásticos e sonhos vazios, medos infundados e preocupações inúteis. [Tradução livre].

Um interessante experimento a se realizar nessa temática seria pedir para a pessoa parar de fazer o que quer que esteja fazendo, desligar o "computador" de sua cabeça e prestar atenção ao que está ouvindo no ambiente, ao que está cheirando, ao que está enxergando, enfim, ao que está percebendo do que acontece a sua volta, sem interpretar, premeditar ou racionalizar sobre tudo, melhorando, dessa forma, a qualidade de seu contato no ambiente.

Na entrevista individual, trouxemos essa questão para trabalhar com Fabiana. Ela nos disse sobre sua experiência numa aula de Sensibilidade (ela é aluna de Licenciatura em Dança) em que, de olhos fechados, deslizava a mão sobre diferentes sentidos, testava diferentes tipos de toques e abraçava os colegas tentando adivinhar quem era e, nessa oportunidade, ela procurava cheirá-los. Fabiana relatou que desde então "tenta sentir o perfume das pessoas que me abraçam”.

Nota-se que, pelo caso relatado no parágrafo anterior, houve um aumento na capacidade de percepção de um ambiente ou, em termos gestálticos, uma melhora na fronteira de contato entre organismo e meio; tal melhora pode trazer melhoras em outras questões existenciais da pessoa, pois a Gestalt-terapia parte tanto do princípio de que as várias esferas de vida da pessoa são intercomunicantes, e a melhora em uma área vivencial pode resultar na melhora de outras áreas da vida da pessoa (Fagan, 1980, p. 125), quanto de que "A descoberta pelo indivíduo de suas sensações (...) pode ajudar a completar o processo de elaboração e a estimular a recuperação de antigos eventos" (Polster, 1980, p. 109).

\subsection{Autonomia pessoal}

A partir de uma indicação do facilitador do grupo pois num trabalho grupal (Rogers, 2002), a autoexposição 
do facilitador pode ajudar na autoexposição dos outros participantes - discutimos na sessão literária de O perfume sobre a capacidade de Grenouille se mostrar tão independente das outras pessoas - ao se isolar por sete anos no ponto mais distante do planeta - que apresentou um extremo nível de autonomia pessoal (self-suport). Raquel escreveu, em sua versão de sentido, que "toda a discussão sobre a necessidade ou não de o homem se isolar foi muito relevante porque hoje não desgrudamos de nossos celulares e das redes sociais na internet”.

Na sessão literária de O grande Gatsby, com o desenrolar da discussão, a temática sobre o estar bem consigo mesmo também apareceu, através das falas de Raquel - que não sente necessidade de estar a toda hora com outras pessoas e Sueli (que aproveita a própria companhia). Na versão de sentido correspondente, Raquel escreve que "no fim, gosto de ser um pouco reservada como o Sr. Nick Carraway".

Em Gestalt-terapia (Perls, 1977; 1980), é necessária a busca de uma melhor autonomia e independência por parte da pessoa, principalmente aquela que apresenta um comportamento neurótico, isto é, um comportamento de manipulação do ambiente e de outras pessoas para satisfazer suas necessidades, em vez de mobilizar seus próprios recursos, seu potencial e sua energia criadora para a satisfação dessas necessidades.

Sem deixar de reconhecer que a pessoa se desenvolve num processo comunitário de relação com o outro, a Gestalt-terapia contribui com a percepção da diferença entre uma relação de complementaridade mútua e uma relação de dependência e controle.

No poema Brinquedos para homens, Carlos Drummond de Andrade (1902-1987) expressa essa duplicidade de sentido, de um lado, a autonomia saudável para a pessoa, de outro, a denúncia contra o capitalismo de consumo - a qual explicitamos na unidade de significado sobre a normatização da sociedade - que nos impele à aquisição ferrenha de mercadorias alheias às nossas necessidades:

Embora eu seja adulto / não me seduzem os brinquedos eletrônicos / que a moda, irônica, me oferece / E excogito: / Que brinquedo inventar para o adulto / privativo dele, sangue e riso dele/brinquedo desenganado mas eficiente? / Tenho de inventar o meu brinquedo / mola saltando no meu íntimo / alegria gerada por mim mesmo / e fácil, fluida, pluma / pétala / Sem o pedir às máquinas e aos deuses / que cada um invente o seu brinquedo (Andrade, 2004, p. 151, grifo nosso).

Tal reflexão advinda do poema nos provoca pensamentos de como podemos fortalecer (para falar em termos da terapia gestáltica) o nosso self e a nossa relação de criatividade com o mundo.

Durante a sessão de $O$ perfume, refletiu-se como, atualmente, estamos necessitados de outras pessoas para nos divertir, para mostrar que estamos felizes (fotografando nossos momentos de alegria e publicando nas redes sociais) manifestando um verdadeiro comportamento neurótico (a busca do reconhecimento do outro, de seu elogio, de sua admiração, de sua aprovação, de sua inveja e etc.), sem conseguir "gerar alegria por si mesmo", sem ter tempo para estar consigo mesmo ou, como escreveu Samara em sua versão de sentido, "toda pessoa precisa ter momentos a sós, para se autoconhecer, conhecer suas limitações”.

\section{As versões de sentido}

Embora tenhamos citado frases e colocações, oriundas das versões de sentido escritas pelas participantes, ao longo das explanações das unidades de significados coletadas nas sessões literárias, decidimos dedicar um subitem específico às versões de sentido.

Na primeira sessão literária (Orgulho e preconceito), reparamos que a versão de sentido escrita pelas participantes não cumpriu seu objetivo primeiro, que seria o de relatar a própria experiência imediata após o encontro.

A maioria dos relatos escritos deteve-se em aspectos históricos e objetivos da obra. Todavia, consideramos essa "fuga" ao relato e o abrigo na identificação de aspectos da obra lida como uma questão inicial inerente à dificuldade de escrever sobre si próprio, sobre seus sentimentos, atividade a qual as participantes não estavam acostumadas.

Por outro lado, Bárbara conseguiu dar um tom de pessoalidade em sua versão de sentido quando se questionou "Como eu, mulher, Bárbara, sou vista na comunidade em que convivo?"

Na segunda sessão literária (O perfume), embora houvesse ainda certa insistência de descrição de trechos da obra, notamos que houve uma maior disponibilidade para a autoexposição no relato escrito.

Raquel escreveu que ficou empolgada quando expôs um ponto de vista que foi aceito em tom de concordância por outra participante. Bárbara escreveu que "A cada encontro me sinto mais a vontade para colocar minhas ideias”. Fabiana, em referência à passagem que Grenouille se isola na montanha, confessou que se sentiu angustiada com essa parte, pois isso "era uma imersão dentro dele muito grande".

Na terceira sessão literária ( $O$ grande Gatsby), percebemos como as participantes conseguem se expressar de forma mais direta em relação a si mesmas, contribuindo com uma awareness mais ampla a respeito do próprio ser.

Raquel chega a "diagnosticar" aquele grupo participante - "creio eu todos nós três temos pelo menos mais de $30 \%$ de temperamento melancólico" - e que tem a intenção de trabalhar seu autoconhecimento, uma vez que tenha escrito que "Pretendo ler mais livros com personagens que se pareçam mais comigo”. Já Sueli reconhece algumas de suas limitações pessoais ao refletir "sobre a nossa vida cotidiana. Como fatos que ocorreram no passado acabam influenciando atitudes, sentimentos atuais e até futuros. No meu caso, me fez pensar como tenho 
dificuldade de esquecer situações que me incomodaram”, ao mesmo tempo em que também, tal como Raquel, expressa um desejo de autoaperfeiçoamento (crescimento pessoal) ao escrever que "Tentarei me livrar um pouco dessa 'mania' [não esquecer situações que a incomodaram]. Certamente isso me fará bem”.

Dessa forma, pelo demonstrado nas entrevistas individuais, podemos dar-nos conta de como as versões de sentido - para além do bem-estar implícito que pode proporcionar no seu ato em si, que é o de escrever sobre a própria experiência - também pode fornecer ótimo material de trabalho no setting terapêutico (individual ou grupal), através de intervenções verbais e experimentos comportamentais.

\section{Conclusão}

Durante todo o processo da pesquisa, chamaram-nos a atenção alguns aspectos emergentes, a saber, a dificuldade de execução conjunta entre a redução fenomenológica e a intervenção psicológica (quando e se necessária) e a dupla importância de uma atividade como um clube de leitura, com um viés de atividade extracurricular e um viés terapêutico.

Em relação à redução fenomenológica, sentimos dificuldade em colocar esse método em prática nesse contexto que se constituía também de possíveis intervenções terapêuticas. A redução fenomenológica, pelo seu caráter intrínseco, consiste num distanciamento temporário das teorias que sustentam a ação requerida, enquanto que a intervenção terapêutica é em si mesma a própria ação.

Essa dificuldade de compatibilidade entre redução e intervenção se complementa na própria postura que os participantes (do Clube do Livro Identidade) assumem enquanto grupo, isto é, no autoquestionamento sobre se é um grupo de leitura ou um grupo terapêutico. Deparamo-nos com essa dificuldade no momento em que pedimos maior autorrevelação por parte de uma participante e ela se negou "a ir por esse caminho". Ora, mesmo em um momento formal de uma terapia grupal qualquer, um participante tem autonomia de se recusar a se expor de tal maneira quando se sentir desconfortável. Contudo, acreditamos que as intervenções teriam maior efeito e as participantes apresentariam maior adesão e disponibilidade pessoal nos exercícios propostos se o grupo se assumisse, desde o início, como um grupo terapêutico (na entrevista individual, Raquel chegou a expressar sua opinião de que o grupo funcionaria melhor psicologicamente se desde o início o facilitador trouxesse temas específicos a serem trabalhados).

Quanto à importância de uma atividade como um clube de leitura, algumas observações podem ajudar a refletir sobre a demanda dessa atividade. No desenrolar do recrutamento de participantes para a pesquisa, o número de voluntários ultrapassou a cota planejada de 15 participantes, situação que nos remeteu à necessidade de fazer uma seleção dos inscritos. Com a notícia do Clube do Livro no site do IFB, tivemos interessados de outros campi e mesmo de fora da instituição que se dispuseram / quiseram participar da pesquisa. Servidores de outras unidades nos contataram querendo saber mais sobre o projeto e da possibilidade de implantar essa iniciativa em suas unidades de ensino.

Isso nos indica que a escola e demais meios acadêmicos carecem de espaços com atividades extracurriculares voltadas a uma forma alternativa, lúdica e de interação social - oportunidades para "ler e compartilhar com outras pessoas” (Raquel) ou uma atividade não ministrada por um professor (Bárbara) - sem deixarem de ser, por isso mesmo, intelectualizadas. Não foi objetivo deste trabalho verificar a possibilidade de um clube de leitura funcionar como atividade extracurricular no âmbito acadêmico, mas não poderíamos deixar de notar a importância que tal atividade pode representar e o apelo da falta que tais iniciativas fazem nesse ambiente.

O Clube do Livro Identidade, desde seu início, inspirou a criação de outro clube de leitura (no Campus Gama do IFB) e, atualmente, decidiu por continuar suas reuniões - agora desvinculadas da formalidade de uma pesquisa acadêmica - com outra coordenação e novos membros participantes.

A respeito da finalidade terapêutica - sempre pensando no amplo sentido que demos a esse termo, para além de sua finalidade de cura de sintomas - o Clube do Livro Identidade mostrou-se como um instrumento de rica potencialidade.

Na sessão de feedback, Raquel sentiu que "As discussões são boas para o crescimento pessoal". Samara foi mais contundente. Fazendo uma relação com o contexto que está vivendo com os filhos gêmeos, afirmou, sobre nosso grupo, que "Me trouxe mais uma terapia; 'terapia', essa é a palavra".

As entrevistas individuais foram ainda mais reveladoras. Sueli ressaltou que esse tipo de atividade "faz você repensar muita coisa (...) como eu sou, como eu vejo as coisas”. Sueli citou a situação de como comparou sua opinião com a opinião do restante do grupo no decorrer das sessões e afirmou que descobriu mais de si mesma, como uma pessoa "descolada”. Fechando com Bárbara, a respeito de suas reflexões posteriores aos encontros, inicialmente hesitou quanto ao caráter terapêutico do grupo, porém, depois chegou a outra conclusão: "reflexivo, talvez não terapêutico porque... não, talvez terapêutico, porque quando você faz a reflexão e muda né?!, você melhora, você evolui como pessoa então, terapêutico sim!”. No final de todas as entrevistas individuais, invariavelmente a conversa caminhou para temas mais íntimos das participantes.

À guisa de conclusão, percebemos como são necessárias maiores iniciativas (como a do clube do livro), promotoras de autonomia e reflexão, que visam a incrementar saúde mental e bem-estar subjetivo, em diversos ambientes e contextos, que não sejam somente no âmbito da clínica tradicional particular. 


\section{Referências}

Abbagnano, N. (2007). Dicionário de Filosofia. ( $5^{\mathrm{a}}$ Ed.). São Paulo: Martins Fontes.

Amatuzzi, M. M. (1996). O uso da versão de sentido na formação e pesquisa em psicologia. Em R. M. L. L. Carvalho (Org.). Repensando a formação do psicólogo: da informação à descoberta (p. 11-24). Campinas - SP: Alínea.

Anderson, P. (1999). As origens da pós-modernidade. Rio de Janeiro: Zahar.

Andrade, C. D. (2004). Amar se aprende amando (28 Ed.). Rio de Janeiro: Record.

Bloom, H. (1991). Cabala e crítica. Rio de Janeiro: Imago.

Bloom, H. (2003). Um mapa da desleitura (2 $2^{\mathrm{a}}$ Ed.). Rio de Janeiro: Imago.

Enright, J. B. (1980). Adestramento da conscientização nas profissões relacionadas com a saúde mental. Em: J. Fagan \& I. L. Shepherd (Orgs.). Gestalt-terapia: teoria, técnicas e aplicações ( $4^{\mathrm{a}}$ Ed.). (p. 341-355). Rio de Janeiro: Zahar.

Fagan, J. (1980). As tarefas do terapeuta. Em: J. Fagan \& I. L. Shepherd (Orgs.). Gestalt-terapia: teoria, técnicas e aplicações (4 $4^{\mathrm{a}}$ Ed.). (p. 123-148). Rio de Janeiro: Zahar.

Fonseca, A. H. L. (2005). Gestalt-terapia fenomenológico existencial. Maceió: Pedang.

Freire, J. C. (2000). Uma leitura da leitura através da Recherche de Proust. Revista de Letras da Universidade Federal do Ceará, Fortaleza - CE, v. 1/2, n. 21, p. 17-25.

Holanda, A. F. (2003). Pesquisa Fenomenológica e Psicologia Eidética: elementos para um entendimento metodológico. M. A. T. Bruns \& A. F. Holanda (Orgs.). Psicologia e Fenomenologia: reflexões e perspectivas (p. 41-64). Campinas SP: Alínea.

Leite, D. M. (2002). Psicologia e literatura. São Paulo: Unesp.

Martins, J. (1992). Um enfoque fenomenológico do currículo: a educação como poiésis. São Paulo: Cortez.

Martins, J. \& Bicudo, M. A. (1989). A pesquisa qualitativa em psicologia. São Paulo: Moraes.

Moreira, D. A. (2002). O método fenomenológico na pesquisa. São Paulo: Pioneira Thomson.

Naranjo, C. (1980). Centralidade no presente: técnica, prescrição e ideal. Em: J. Fagan \& I. L. Shepherd (Orgs.). Gestalt-terapia: teoria, técnicas e aplicações (4⿳亠丷厂 Ed.). (p. 71-100). Rio de Janeiro: Zahar.

Paixão, D. L. L. (2002). Quando Ler é transformar-se: um estudo fenomenológico do processo de aquisição da leitura. Dissertação de Mestrado, Universidade Católica de Brasília, Brasília - DF, Brasil.

Perls, F. S. (1977). Gestalt-terapia explicada. (8ª Ed.). São Paulo: Summus.
Perls, F. S. (1980). Quatro palestras. Em: J. Fagan \& I. L. Shepherd (Orgs.). Gestalt-terapia: teoria, técnicas e aplicações ( $4^{\mathrm{a}}$ Ed.). (p. 27-60). Rio de Janeiro: Zahar.

Perls, F. S. (1988). A abordagem gestáltica e a testemunha ocular da terapia. ( $2^{\mathrm{a}}$ Ed.). Rio de Janeiro: Guanabara.

Perls, F. S.; Goodman, P. \& Hefferline, R. (1997). Gestalt-terapia. ( $2^{\mathrm{a}}$ Ed.). São Paulo: Summus.

Polster, E. (1980). Funcionamento sensorial em psicoterapia. Em: J. Fagan \& I. L. Shepherd (Orgs.). Gestalt-terapia: teoria, técnicas e aplicações (4ª Ed.). (p. 101-109). Rio de Janeiro: Zahar.

Polster, E. \& Polster, M. (2001). Gestalt-terapia integrada. São Paulo: Summus.

Proust, M. (1991). Sobre a leitura. (2 Ed.). São Paulo: Pontes.

Resnick, S. (1977). Gestalt-terapia como prática meditativa. Em: J. Stevens (Org.). Isto é Gestalt ( $4^{\mathrm{a}} \mathrm{Ed}$.). (p. 295-301). São Paulo: Summus.

Rogers, C. R. (2002). Grupos de encontro. (2ª Ed.). São Paulo: Martins Fontes.

Silva, S. S. (2008). O caleidoscópio Glauco Mattoso. Tese de Doutorado, Faculdade de Letras, Universidade Federal de Alagoas, Maceió - AL, Brasil.

Thera, N. (2005). The heart of buddhist meditation: a handbook of mental training based on the Buddha's way of mindfulness. London: Buddhist Publication Society. (Original publicado em 1962).

Torre, I. P. P. B. (2012). Clubes virtuais de leitura: práticas e competências leitoras. Tese de Doutorado, Universidade do Minho. Braga, Portugal.

Diego Paulino Galhardo - Mestrando do Programa Stricto Sensu em Psicologia da Universidade Católica de Brasília (UCB). Email: galhardodiego@gmail.com

Ondina Pena Pereira - Doutora em Antropologia pela Universidade de Brasília (UnB), Professora e Pesquisadora do Programa de Pós-Graduação Stricto Sensu em Psicologia da Universidade Católica de Brasília (UCB). Email: ondinapena@gmail.com

Recebido em 23.07.15 Primeira Decisão Editorial em 13.01.16 Aceito em 03.03.16 